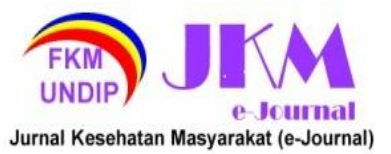

JURNAL KESEHATAN MASYARAKAT (e-Journal)

Volume 9, Nomor 6, November 2021

ISSN: 2715-5617 / e-ISSN: 2356-3346

http://ejournal3.undip.ac.id/index.php/jkm

\title{
HUBUNGAN ANTARA KARAKTERISTIK DEMOGRAFI PEKERJA, BEBAN KERJA MENTAL, DAN GAYA KEPEMIMPINAN TERHADAP BURNOUT PADA STAFF ADMINISTRASI FKM UNDIP
}

\author{
Mutiara Putri Masduki ${ }^{*}$, Ekawati ${ }^{2}$, Ida Wahyuni ${ }^{2}$ \\ ${ }^{1}$ Mahasiswa Peminatan Keselamatan dan Kesehatan Kerja Fakultas Kesehatan Masyarakat \\ Universitas Diponegoro Jl. Prof. H. Soedarto, S.H.,Tembalang, Semarang, Indonesia \\ 2Bagian Keselamatan dan Kesehatan Kerja Fakultas Kesehatan Masyarakat Universitas Diponegoro \\ J. Prof. H. Soedarto, S.H.,Tembalang, Semarang, Indonesia \\ ${ }^{*}$ Corresponding author : mutiaramasduki@gmail.com
}

\begin{abstract}
Burnout is physical, mental, and emotional exhaustion that occurs continuously which causes a person to lose motivation at work until appears the behavior of withdrawing from work to the desire to stop working, burnout is also caused by a mismatch between job demands and the rewards received. In carrying out work, it is not uncommon for workers to experience physical or mental exhaustion to experience prolonged stress. This prolonged stress is also known as burnout. Burnout sufferers are often found in public service workers such as teachers, police, nurses, and administrative workers are no exception. Administrative staffs are quite vulnerable to burnout because administrative staffs are required to work calmly, carefully, thoroughly, and able to work with a team. The factors that influence burnout consist of internal and external factors. Internal factors consist of demographic characteristics (age, gender, marital status, education, and years of service), personal characteristics (personality characteristics), and the attitude of how a person responds to his work (job attitude). Meanwhile, external factors consist of job characteristics, occupational characteristics, and organizational characteristics. The purpose of this study was to determine the relationship between the demographic characteristics of workers (age, gender, marital status, education, years of service), mental workload, and leadership style on burnout. This research is a quantitative correlation study using a cross sectional design. The population of this study is the administrative staffs of Faculty of Public Health Diponegoro University with the sampling technique used is total sampling and the data analysis used is univariate and bivariate analysis. The result of this study is that there are no significant relationship between age, gender, marital status, education, years of service, mental workload, and leadership style with burnout.
\end{abstract}

Keywords : burnout, mental workload, leadership syle, demographic characteristics

\section{PENDAHULUAN}

Setiap badan usaha atau perusahaan

wajib menerapkan Keselamatan dan Kesehatan Kerja di setiap tempat kerjanya demi menciptakan tempat kerja yang aman, nyaman, dan sehat bagi pekerjanya. Hal tersebut bertujuan agar produktivitas setiap pekerja dapat meningkat. Selain untuk memberikan perlindungan dan jaminan keselamatan dan kesehatan bagi pekerja juga untuk melindungi lingkungan di sekitar perusahaan dari kerusakan dan masyarakat di sekitarnya. ${ }^{1}$ Sudah diterangkan di dalam Undang-Undang Republik Indonesia Nomor 1 Tahun 1970 Tentang Keselamatan Kerja bahwa K3 bertujuan untuk memberikan perlindungan dan jaminan keselamatan kepada tiap - tiap tenaga kerja dan juga orang lain di tempat kerja, menjamin semua sumber produksi dapat dipergunakan dengan aman dan efisien, serta dapat meningkatkan kesejahteraan dan produktivitas nasional. ${ }^{2}$
Di dalam setiap perusahaan, baik lingkup pemerintah ataupun swasta agar tujuan perusahaan berhasil tercapai dan perusahaan mempu berjalan dengan baik maka perlu adanya pembagian kerja atau tugas, pembagian wewenang, hingga detail tugas dari setiap bagian yang ikut terlibat di kegiatan perusahaan tersebut. Selain itu, perusahaan harus menetapkan kaitan kerja sama dari satu aspek ke aspek lainnya, sebagai pedoman bagi orang - orang yang melaksanakan, agar pelaksanaan dapat dilakukan sistematis. Untuk melakukan rangkaian aktivitas dalam perusahaan yang dilakukan oleh para pekerja dan pegawai, agar tujuan yang telah ditetapkan tercapai, secara utuh dibutuhkan pekerjaan kantor yang rapi, tertib, dan lancar. Oleh sebab itu dibutuhkan suatu prasarana yaitu gedung kantor yang bisa memberikan informasi yang tepat, berdasarkan fakta, dan diperlukan oleh 


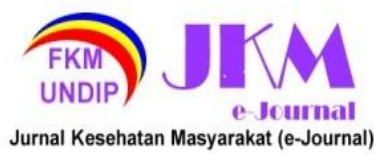

pimpinan untuk mengelola dan mengontrol usahanya. $^{3}$

Keselamatan dan Kesehatan Kerja atau biasa disingkat K3 wajib diterapkan di semua tempat dan lingkungan kerja tidak terkecuali lingkungan perkantoran. Dijelaskan dalam Peraturan Menteri Kesehatan Republik Indonesia Nomor 48 Tahun 2016, perkantoran merupakan suatu bangunan yang memiliki fungsi untuk melakukan aktivitas perkantoran bagi karyawan baik bangunan yang bertingkat maupun tidak bertingkat. ${ }^{4}$ Oleh karena itu dibuatlah suatu regulasi standar mengenai K3 Perkantoran untuk pimpinan ataupun pengelola kantor dalam upaya melaksanankan K3 di perkantoran dengan tujuan menciptakan lingkungan kantor yang sehat, aman, dan nyaman agar pekerja menjadi selamat, sehat, bugar, berkinerja, serta produktif. ${ }^{5}$

Salah satu bidang pekerjaan yang identik dengan lingkungan perkantoran adalah administrasi. Administrasi secara sederhana dapat diartikan dengan suatu sistem menyusun dan mencatat informasi dan data dengan cara sistematis dalam rangka menyediakan dan memberikan data informasi serta memudahkan dalam mendapatkan informasi dan data kembali secara utuh dan menyeluruh dan terhubung satu sama lain. Data dan informasi yang disinggung adalah terkait dengan kegiatan organisasi, baik untuk keperluan eksternal maupun internal. Administrasi secara sederhana dapat disebut sebagai tata usaha. Orang-orang yang berkecimpung dalam bidang ini biasa disebut satff administrasi atau tata usaha. Staff administrasi di sebuah fakultas merupakan tenaga non pendidik, misalnya kepala tata usaha, staff perpustakaan, staff keuangan, staff laboratorium terpadu, staff akademik hingga security. Para staff administrasi ini sebagai tenaga pendukung dan pelayanan dalam kegiatan perkuliahan memiliki peran dan tanggung jawab untuk mewujudkan kegiatan perkuliahan yang lancar. Oleh karena itu staff administrasi di fakultas tidak hanya menjadi pengelola administratif tetapi juga menjadi tenaga ahli dalam melaksanakan profesionalitasnya di bidang masing-masing. ${ }^{6}$

Dalam menjalani pekerjaan tidak jarang para pekerja mengalami kelelahan fisik ataupun mental hingga mengalami stress berkepanjangan. Stress berkepanjangan ini disebut juga dengan istilah burnout. Penderita burnout banyak ditemukan pada pekerja pelayanan umum seperti guru, polisi, perawat, dan tidak terkecuali para pekerja administrasi. Tuntutan pekerjaan yang tinggi mengakibatkan pekerja administrasi harus mampu mengontrol keadaan fisik dan mentalnya. Hal tersebut bertujuan agar dapat mencapai hasil yang maksimal dalam bekerja. ${ }^{7}$ Menurut World Health Organization (WHO) burnout adalah suatu sindrom sebagai akibat dari stres kronis yang gagal dikelola oleh setiap individu. Jika hal tersebut terjadi terus-menerus dalam kurun waktu yang lama maka akan menyebabkan emosi yang tidak terkontrol, tidak sehat secara mental, dan munculnya pikiran negatif hingga pada akhirnya dapat membuat pekerja kehilangan minat dan motivasi. ${ }^{8}$

Maslach, Schaufeli, dan Leither menjelaskan bahwa ada dua faktor yang memengaruhi burnout, faktor tersebut adalah faktor internal dan faktor eksternal. Faktor internal terdiri dari karakterisitik demografi, karakteristik pribadi atau personality characteristic, dan sikap kerja. Karakteristik demografi merupakan suatu karakter seseorang yang berkaitan dengan usia, jenis kelamin, status pernikahan, pendidikan, dan masa kerja. Kemudian ada karakteristik kepribadian dari setiap individu dan sikap kerja (job attitude) yaitu bagaimana seseorang menyikapi pekerjaannya. Sementara faktor eksternal terdiri dari karakteristik pekerjaan, karakteristik jabatan, dan karakteristik organisasi. Karakteristik pekerjaan terkait dengan bagaimana karakter atau sifat dari suatu pekerjaan sebagai contoh apakah pekerjaan tersebut memiliki beban yang tinggi atau tidak. Karakteristik jabatan hal ini terkait dengan peran dan tanggung jawab dari suatu jabatan atau posisi kerja. Lalu untuk karakteristik organisasi berkaitan dengan budaya dari suatu tempat kerja, iklim lingkungan sosial, hingga gaya kepemimpinan atasan. ${ }^{9}$

Sebuah jajak pendapat Gallup pada tahun 2018 berhasil menemukan 23 persen karyawan selalu merasa kelelahan bekerja, sementara 44 persen karyawan menyatakan terkadang merasa burnout. Sebuah survey di Prancis dalam Buletin Mingguan Melsa menyatakan bahwa $61 \%$ pekerja merasa kesal dengan lingkungan kerja yang penuh tekanan. Sementara sebuah penelitian pada 170 manajer manufaktur di India yang dilakukan oleh Madnawat dan Pankaj menghasilkan bahwa keperibadian merupakan sebagai prediktor burnout. Lalu Norlund menyatakan prevalensi tingkat burnout di Swedia Utara yang cukup tinggi $13 \%$ dialami oleh pekerja wanita. ${ }^{10} \mathrm{Di}$ Indonesia penelitian yang dilakukan oleh pengajar dari Jurusan Keperawatan Fakultas IImu-IImu Kesehatan 


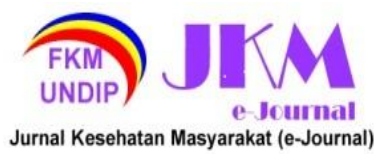

Universitas Jenderal Soedirman pada tahun 2017 terhadap pekerja wanita di wilayah Kabupaten Banyumas menghasilkan bahwa 199 dari 200 pekerja wanita mengalami burnout. ${ }^{11}$ Penelitian penilaian tingkatan burnout, depresi, kecemasan, dan stress yang dilakukan pada bidan di Inggris Raya menunjukkan $83 \%$ bidan mengalami personal burnout dengan nilai sedang hingga tinggi. Sementara $67 \%$ bidan dilaporkan mengalami burnout terkait pekerjaan dengan tingkatan sedang hingga tinggi. ${ }^{12}$

Di masa pandemi Covid-19 saat ini juga telah dilakukan penelitian burnout kepada beberapa kelompok kerja seperti tenaga kesehatan dan tenaga pendidik. Hasilnya, berdasarkan penelitian yang dilakukan oleh tim peneliti dari Program Studi Magister Kedokteran Kerja Universitas Indonesia ditemukan sebanyak $83 \%$ tenaga kesehatan di Indonesia menderita burnout tingkat sedang dan tinggi yang artinya sudah berpotensi memengaruhi produktivitas pekerja. Penelitian lain yang dilakukan kepada guru Anak Berkebutuhan Khusus menghasilkan guru ABK yang mengalami burnout tingkat rendah pada masa pandemi ini sebesar $26,3 \%$, burnout tingkat sedang sebesar $38,4 \%$, dan burnout tingkat tinggi sebesar $35,2 \%$.

Staff administrasi cukup rentan terhadap burnout dikarenakan staff administrasi dituntut untuk bekerja dengan tenang, cermat, teliti, serta mampu bekerjasama dengan tim. Beban kerja mental yang tinggi pun dapat mempengaruhi untuk terjadinya burnout pada staff administrasi. Berdasarkan penelitian yang dilakukan oleh Dionisius Indra Prakoso kepada tenaga kependidikan di suatu Institusi Kependidikan X pada Desember 2017 sampai Februari 2018 menghasilkan sebanyak $72,7 \%$ tenaga kependidikan memiliki beban kerja mental yang sedang, 20,5\% memiliki beban kerja mental yang berat, dan $6,8 \%$ memiliki beban kerja mental yang ringan. ${ }^{13}$ Friska Marla juga menyebutkan dalam hasil penelitiannya pada Pegawai Negeri Sipil (PNS) bagian kependidikan Universitas Jember, bahwa beban kerja mental PNS bagian kependidikan berada pada kategori berat. ${ }^{14}$ Penelitian pada staff tata usaha ruangan di Rumah Sakit Umum Daerah K.R.M.T Wongsonegoro Kota Semarang yang dilakukan oleh Nur Sa'idah juga menemukan sebanyak $47,05 \%$ staff administrasi memiliki beban kerja mental yang tinggi. ${ }^{15}$

FKM Undip merupakan suatu institusi kependidikan yang dapat dikategorikan ke dalam sektor perkantoran. FKM Undip juga merupakan institusi yang menerapkan SMK3 dalam tempat kerjanya. Bahkan telah memiliki sertifikat emas untuk penerapan SMK3. Dengan adanya hal tersebut dapat dilihat bahwa FKM Undip memiliki kesadaran yang tinggi terkait K3 di lingkungan kerjanya. Terbukti dengan adanya sertifikat emas atas penerapan SMK3 yang telah dilakukan. Melihat hal tersebut peneliti ingin mengetahui bagaimana kondisi $\mathrm{K} 3$ jika dilihat dari sisi psikologi di FKM Undip. Oleh karena adanya fenomena mengenai burnout pada pekerja, dan keingintahuan peneliti terkait K3 dari sisi psikologi di FKM Undip dalam hal ini kejadian burnout pada staff administrasi, maka peneliti tertarik untuk meneliti dengan maksud mengetahui dan menganalisis hubungan antara karakteristik demografi pekerja (usia, jenis kelamin, status pernikahan, pendidikan, masa kerja), beban kerja mental, dan gaya kepemimpinan terhadap burnout pada staff administrasi FKM Undip.

\section{METODE PENELITIAN}

Penelitian yang dilakukan ini merupakan penelitian kuantitatif korelasi dengan memakai rancangan cross sectional. Populasi dari penelitian ini yaitu semua staf administrasi FKM UNDIP dengan jumlah 54 orang. Teknik sampling yang dipakai dalam penelitian ini yaitu total sampling. Variabel bebas dalam penelitian ini adalah usia, jenis kelamin, status pernikahan, pendidikan, masa kerja, beban kerja mental, dan gaya kepemimpinan. Sementara variabel terikat dalam penelitian ini adalah burnout. Pengumpulan data dilakukan menggunakan kuesioner yang telah terstandar yakni MBI dan Nasa TLX. Kuesioner Maslach Burnout Inventory (MBI) merupakan kuesioner yang digunakan untuk mengukur burnout, kuesioner Nasa TLX digunakan untuk mengukur beban kerja mental, lalu ada kuesioner untuk mengetahui gaya kepemimpinan dari atasan, serta kuesioner terkait karakteristik staff administrasi (usia, jenis kelamin, status pernikahan, pendidikan, dan masa kerja). Pengumpulan data pada penelitian ini dilakukan secara online dengan memanfaatkan platform google form. Kuesioner akan dibuat dalam bentuk google form kemudian link kuesioner diberikan kepada Kepala Bagian Tata Usaha FKM UNDIP untuk disebarkan kepada seluruh staf administrasi selaku responden penelitian dan diisi. Dalam upaya mengontrol pengambilan data pada responden peneliti juga 


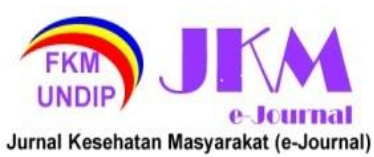

menghubungi responden secara pribadi untuk memonitor secara langsung pengisian kuesioner pada responden.Dalam menganalisis data penelitian digunakan analisis univariat dan bivariat. Analisis univariat merupakan analisis yang dilakukan untuk mengetahui distribusi frekuensi dan proporsi dari setiap variabel bebas dan variabel terikat yang diteliti. Sementara analisis bivariat merupakan analisis yang dilakukan untuk mengetahui hubungan antara dua variabel yaitu variabel bebas (usia, jenis kelamin, status pernikahan, pendidikan, masa kerja, beban kerja mental, dan gaya kepemimpinan) dan variabel terikat (burnout). Pada analisis bivariat menggunakan uji korelasi poin biserial untuk menguji hubungan antara jenis kelamin dan burnout, status pernikahan dan burnout, serta gaya kepemimpinan dan burnout. Uji korelasi dengan kendall's tau $b$ untuk menguji hubungan antara pendidikan dan burnout, serta beban kerja mental dan burnout. Lalu untuk menguji hubungan antara usia dan burnout, serta masa kerja dan burnout menggunakan uji korelasi pearson.

\section{HASIL DAN PEMBAHASAN}

1. Hasil Analisis Univariat

a. Usia

Tabel 1. Distribusi Frekuensi Usia Staf Administrasi FKM UNDIP Tahun 2021

\begin{tabular}{lcc}
\hline \multicolumn{1}{c}{ Usia } & N & $\%$ \\
\hline Muda & 24 & 44,4 \\
Tua & 30 & 55,6 \\
\hline Total & 54 & 100,0 \\
\hline
\end{tabular}

Staf administrasi FKM UNDIP didominasi oleh staf berusia tua ( $\geq 41$ tahun) dengan persentase $55,6 \%$.

b. Jenis Kelamin

Tabel 2. Distribusi Frekuensi Jenis Kelamin Staf Administrasi FKM UNDIP Tahun 2021

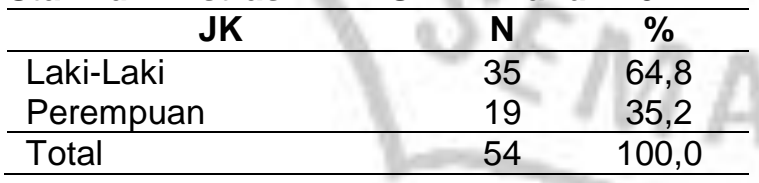

Staf administrasi FKM UNDIP didominasi oleh staf laki-laki dengan persentase $64,8 \%$.

c. Status Pernikahan

Tabel 3. Distribusi Frekuensi Status Pernikahan Staf Administrasi FKM UNDIP Tahun 2021

\begin{tabular}{lcc}
\hline \multicolumn{1}{c}{ Status Pernikahan } & N & $\%$ \\
\hline Belum Menikah & 5 & 9,3 \\
Menikah & 48 & 88,9 \\
Pernah Menikah & 1 & 1,9 \\
\hline
\end{tabular}

\begin{tabular}{lrr}
\hline Total & 54 & 100,0 \\
\hline
\end{tabular}

Staf administrasi FKM UNDIP didominasi oleh staf yang telah menikah dengan persentase $88,9 \%$.

d. Pendidikan

Tabel 4. Distribusi Frekuensi Pendidikan Staf Administrasi FKM UNDIP Tahun 2021

\begin{tabular}{lcc}
\multicolumn{1}{r}{ Pendidikan } & N & $\%$ \\
\hline SMA & 22 & 40,7 \\
Perguruan Tinggi & 32 & 59,3 \\
\hline Total & 54 & 100,0 \\
\hline
\end{tabular}

Staf administrasi FKM UNDIP didominasi oleh staf dengan lulusan pendidikan Perguruan Tinggi (akademik, vokasi, profesi) dengan persentase $59,3 \%$.

e. Masa Kerja

Tabel 5. Distribusi Frekuensi Masa Kerja Staf Administrasi FKM UNDIP Tahun 2021

\begin{tabular}{lcc}
\hline \multicolumn{1}{r}{ Masa Kerja } & N & $\%$ \\
\hline Baru & 30 & 55,6 \\
Lama & 24 & 44,4 \\
\hline Total & 54 & 100,0 \\
\hline
\end{tabular}

Staf administrasi FKM UNDIP didominasi oleh staf dengan masa kerja baru dengan persentase $55,6 \%$.

f. Beban Kerja Mental

Tabel 6. Distribusi Frekuensi Beban Kerja Mental Staf Administrasi FKM UNDIP Tahun 2021

\begin{tabular}{lcc}
\hline Beban Kerja Mental & N & $\%$ \\
\hline Rendah & 13 & 24,1 \\
Sedang & 28 & 51,9 \\
Tinggi & 13 & 24,1 \\
\hline Total & 54 & 100,0 \\
\hline
\end{tabular}

Tingkat beban kerja mental yang paling banyak pada staf administrasi FKM UNDIP adalah tingkat sedang dengan persentase $51,9 \%$. Dengan hasil temuan bahwa sebesar $51,9 \%$ staf administrasi memiliki beban kerja mental yang sedang, artinya beban kerja mental yang dimiliki oleh staf tidak melebihi atau tidak kurang dari kapasitas yang dimiliki staf. Namun instansi harus tetap memperhatikan pembagian beban kerja mental ini agar tidak mengalami kenaikan sehingga tidak berdampak pada kinerja dan produktivitas dari para staf administrasi. Beban kerja mental yang tidak dibagi dengan baik dapat menyebabkan perasaan lelah, bosan, serta menurunnya kesadaran dan sikap hati hati dalam bekerja. Gejala lain yang menunjukkan adanya beban kerja mental yang tinggi yaitu sulitnya untuk fokus, mudah cemas, mudah marah dan gelisah, hingga 


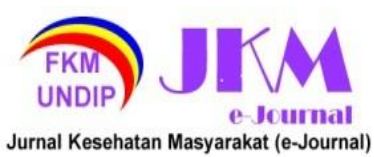

perasaan putus asa. Adapaun gejala yang terjadi pada fisik yaitu terganggunya pola tidur, mudah lelah dan lesu, sakit kepala, sakit pada leher belakang dan punggung, hingga menurunnya nafsu makan. Semua dampak yang diakibatkan oleh beban kerja mental yang tinggi atau melebihi kapasitas pada akhirnya membawa pada produktivitas kerja dan kinerja staf yang menurun.

g. Gaya Kepemimpinan

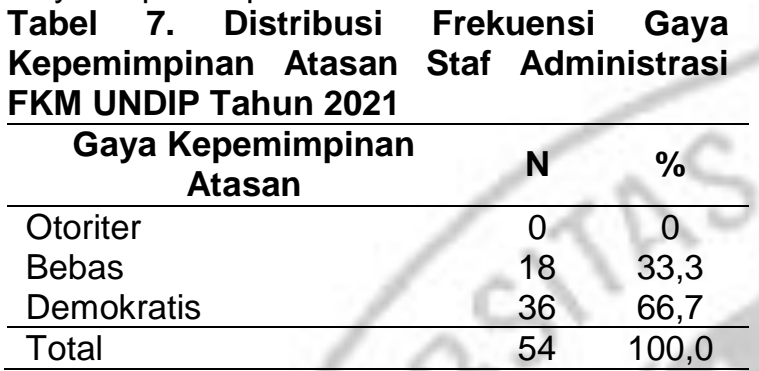

Gaya kepemimpinan atasan yang paling banyak pada staf administrasi FKM UNDIP adalah demokratis dengan persentase $66,7 \%$.

h. Burnout

Tabel 8. Distribusi Frekuensi Burnout Staf Administrasi FKM UNDIP Tahun 2021

\begin{tabular}{lcc}
\hline \multicolumn{1}{c}{ Burnout } & N & $\%$ \\
\hline Rendah & 7 & 13,0 \\
Sedang & 41 & 75,9 \\
Tinggi & 6 & 11,1 \\
\hline Total & 54 & 100,0 \\
\hline
\end{tabular}

Tingkat burnout yang paling banyak pada staf administrasi FKM UNDIP adalah tingkat sedang dengan persentase $75,9 \%$. Dengan temuan staf administrasi sebesar 75,9\% mengalami burnout tingkat sedang menunjukkan bahwa kondisi mental para staf tidak dalam keadaan yang cukup baik. Ini sudah menjadi suatu tanda untuk segera dilakukan perbaikan, jika tidak segera diberikan perbaikan maka tingkat burnout yang dialami oleh staf bisa menjadi lebih tinggi. Semakin tinggi burnout yang dialami oleh staf dapat mengakibatkan kelelahan, kecemasan, fokus yang buruk, depresi, menurunnya kemampuan membuat keputusan, bersikap acuh tak acuh, gangguan muskuloskeletal, hingga kecanduan pada alkohol dan obatobatan terlarang. Dari semua hal tersebut pada akhirnya dapat menurunkan kinerja staf, absen yang meningkat, turnover pada karyawan, menurunnya produktivitas kerja, hingga terjadinya kecelakaan kerja.

\section{Hasil Analisis Bivariat}

a. Hubungan Usia dengan Burnout

Berdasarkan hasil dari uji korelasi Pearson didapatkan nilai $P$-value $=0,761$, ini berarti tidak ada hubungan yang signifikan antara usia dengan burnout dikarenakan $P$ value $>0,05$. Hal ini berbanding terbalik dengan Teori Maslach yang mengatakan orang dengan usia muda lebih berisiko terkena burnout daripada orang yang berusia lebih tua. Hal ini dikarenakan orang - orang pekerja berusia muda lebih idealis dan memiliki harapan dan ekspektasi tinggi kepada pekerjaan serta hidupnya yang bahkan terkadang terkesan kurang realistis. ${ }^{11}$

Tetapi penelitian ini memiliki hasil yang sama dengan penelitian yang dilakukan oleh Vera Indilusiantari R. S. dan Inggit Meliana A. pada tahun 2015 yang menyatakan bahwa tidak adanya hubungan yang signifikan antara umur dengan burnout pada petugas di Direktorat Bina Kesehatan Kerja dan Olahraga Kementerian Kesehatan Republik Indonesia, Jakarta Selatan. ${ }^{16}$

Banyak studi penelitian yang menunjukkan atau memasukkan usia pekerja sebagai faktor yang berhubungan dengan burnout pada pekerja, namun hasilnya belum konklusif. Beberapa penelitian memperlihatkan bahwa ada hubungan antara usia dengan burnout sementara yang lainnya memperlihatkan tidak adaya hubungan antara usia dengan burnout. Adanya perbedaan pada hasil penelitian terutama pada kelompok kerja yang berbeda bisa terjadi karena perbedaan budaya tempat kerja, perbedaan dalam karakteristik individu dalam lini kerja yang berbeda, dan perbedaan dalam standar atau regulasi. ${ }^{17}$

b. Hubungan Jenis Kelamin dengan Burnout

Berdasarkan dari hasil uji korelasi Poin Biserial diperoleh nilai $P$-value $=0,713$, ini berarti tidak adanya hubungan yang signifikan antara jenis kelamin dengan burnout dikarenakan $P$-value $>0,05$. Hal ini berbanding terbalik dengan teori yang disampaikan oleh Ivanccevich bahwa perempuan lebih berisiko menderita burnout daripada laki-laki. Hal ini dikarenakan laki-laki memiliki kecenderungan tumbuh besar dengan ditanamkan nilai kemandirian sehingga nantinya laki-laki dapat berisikap tegas, kuat, logis, dan tidak emosional. ${ }^{16}$

Namun penelitian ini memiliki hasil yang sama dengan penelitian yang dilakukan oleh Indah Mawarti dan Yusnilawati pada tahun 2017 yang mengatakan tidak ada hubungan antara jenis kelamin dengan tingkat 


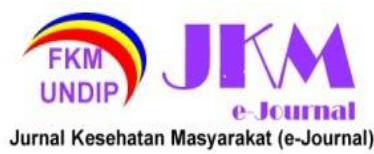

burnout yang terjadi pada perawat di ruang instalasi rawat inap Rumah Sakit Umum Daerah Raden Mattaher dan Rumah Sakit Abdul Manap Jambi tahun 2017. ${ }^{18}$

Pada era sekarang ini laki-laki ataupun perempuan mempunyai tuntutan dan kebutuhan serta tanggung jawab yang juga sama besar di tempat kerja. Kesadaran mengenai kesetaraan gender yang semakin tinggi di kalangan masyarakat dan juga pekerja membuat laki-laki dan perempuan pada akhirnya memiliki tuntutan yang sama besar dalam upaya memenuhi kebutuhannya dengan bekerja. ${ }^{19}$

c. Hubungan Status Pernikahan dengan Burnout Berdasarkan hasil dari uji korelasi Poin Biserial didapatkan nilai $P$-value $=0,079$, yang berarti tidak ada hubungan yang signifikan antara status pernikahan dan burnout dikarenakan $P$-value $>0,05$. Hal ini berbanding terbalik dengan teori yang disampaikan Maslach dan juga Wills bahwa orang dengan status pernikahan belum menikah lebih berisiko terkena burnout daripada orang yang telah menikah. ${ }^{20}$

Tetapi penelitian ini memiliki hasil yang sama dengan penelitian yang dilakukan oleh Keksi Girindra Swasti, Wahyu Ekowati, dan Eni Rahmawati pada tahun 2017 yang mengatakan bahwa responden yang telah menikah maupun responden yang belum menikah memiliki potensi yang sama untuk mengalami burnout. Status pernikahan berkaitan dengan dukungan yang didapatkan dari pasangan. Bagi para pekerja yang berstatus belum menikah atau lajang bisa mendapatkan dukungan sosial dari keluarga maupun teman-teman. Ditambah lagi cukup umum ditemukan di Indonesia pekerja lajang yang juga seorang anak masih tinggal bersama dengan keluarga walaupun sudah memasuki usia dewasa. Sehingga walaupun berstatus belum menikah tetap mendapatkan dukungan dari keluarga dan juga temanteman. ${ }^{11}$

d. Hubungan Pendidikan dengan Bunrout

Berdasarkan hasil dari uji statistik dengan menggunakan uji korelasi Kendall's tau $b$ didapatkan nilai $P$-value $=0,814$, ini berarti tidak adanya hubungan yang signifikan antara pendidikan dengan burnout dikarenakan $P$-value $>0,05$. Hal ini berbanding terbalik dengan teori yang disampaikan oleh Maslach, Schaufeli, dan Leither bahwa ketika tingkat pendidikan seseorang semakin tinggi maka level burnout yang dideritanya juga semakin tinggi. ${ }^{9}$
Namun penelitian ini memiliki hasil yang sama dengan penelitian yang dilakukan oleh Indah Mawarti dan Yusnilawati pada tahun 2017 yang mengatakan tidak adanya hubungan antara tingkat pendidikan dengan tingkat burnout yang terjadi pada perawat di ruang instalasi rawat inap Rumah Sakit Umum Daerah Raden Mattaher dan Rumah Sakit Abdul Manap di Jambi pada tahun 2017. ${ }^{18}$

Dari hasil tabulasi silang dapat diketahui bahwa burnout baik dari tingkat rendah, sedang, maupun tinggi prevalensinya lebih banyak pada staf dengan lulusan Perguruan Tinggi. Tingkat pendidikan seseorang berbanding lurus dengan tanggung jawab dan peran. Semakin tinggi tingkat pendidikan, maka semakin besar pula peran dan tanggung jawab yang dipikul. ${ }^{11}$

e. Hubungan Masa Kerja dengan Burnout

Berdasarkan hasil dari uji statistik dengan menggunakan uji korelasi Pearson diperoleh nilai $P$-value $=0,168$, artinya tidak ada hubungan yang signifikan antara masa kerja dengan burnout dikarenakan $P$-value $>$ 0,05 . Hal ini berbanding terbalik dengan teori yang disampaikan Maslach, Schaufeli, dan Leither bahwa tidak ada lamanya masa kerja yang benar-benar spesifik yang mengakibatkan burnout. Namun semakin lama waktu seseorang bekerja maka semakin tinggi risiko terjadi burnout. ${ }^{9}$

Namun hasil penelitian ini sejalan dengan penelitian yang dilakukan oleh Indah Mawarti dan Yusnilawati pada tahun 2017 yang mengatakan tidak terdapat hubungan antara masa kerja dengan tingkat burnout pada perawat di ruang instalasi rawat inap RSUD Raden Mattaher dan Rumah Sakit Abdul Manap Jambi tahun 2017. ${ }^{18}$

Dari hasil tabulasi silang dapat diketahui bahwa burnout baik dari tingkat rendah, sedang, maupun tinggi didominasi oleh staf dengan masa kerja masih baru. Individu dengan masa kerja yang masih baru memiliki kecenderungan untuk lebih mudah merasa jenuh, hal tersebut dikarenakan individu dengan masa kerja baru masih berada dalam tahap adaptasi dan upaya untuk menguasai pekerjaannya. Maka semakin lama masa kerja, individu akan semakin menguasai pekerjaannya serta semakin banyak pengalamannya dengan pekerjaannya.

f. Hubungan Beban Kerja Mental dengan Burnout

Berdasarkan hasil dari uji statistik dengan menggunakan uji korelasi Kendall's tau $b$ diperoleh nilai $P$-value $=0,991$, artinya tidak ada hubungan yang signifikan diantara 


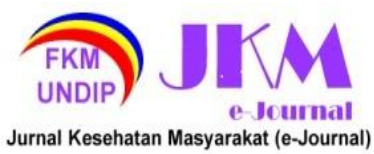

beban kerja mental dengan burnout dikarenakan $P$-value $>0,05$. Hal ini berbanding terbalik dengan teori yang disampaikan oleh Sutjipto yang mengatakan bahwa beban kerja yang berlebihan baik itu kuantitatif ataupun kualitatif harus segera ditangani, karena beban kerja yang melampaui kapasitas pekerja dapat memberikan ketegangan emosional bagi pekerja. ${ }^{16}$

Namun penelitian ini memiliki hasil yang sama dengan penelitian yang dilakukan oleh Moch. Zulfiqar Afifuddin Rizqiansyah pada tahun 2017 yang mengatakan beban kerja fisik dan beban kerja mental tidak bisa menjadi penentu kejenuhan kerja (burnout) pada karyawan PT Jasa Marga (Persero) Tbk cabang Surabaya Gempol. Penelitian ini juga memiliki hasil yang sama dengan penelitian yang dilakukan oleh Rieska Ernawati pada tahun 2019 yang menghasilkan tidak adanya pengaruh antara beban kerja mental dan beban kerja fisik terhadap burnout. Walau demikian beban kerja mental tetap dapat meningkatkan risiko terjadi burnout di tempat kerja. Tekanan kerja yang melampaui kapasitas pekerja dapat menjadi sumber burnout bagi pekerja. ${ }^{21,22}$

g. Hubungan Gaya Kepemimpinan dengan Burnout

Berdasarkan hasil dari uji korelasi Poin Biserial diperoleh nilai $P$-value $=0,442$, artinya tidak adanya hubungan yang signifikan antara gaya kepemimpinan atasan dengan burnout dikarenakan $P$-value $>0,05$.

Penelitian ini memiliki hasil yang sama dengan penelitian yang dilakukan oleh Teuku Reza Budiansya pada tahun 2015 yang menyatakan tidak adanya hubungan yang signifikan antara gaya kepemimpinan otokratis, demokratis, atau laissez-faire yang diterapkan oleh pimpinan ruangan dengan burnout pada perawat yang bertugas di ruang rawat inap Rumah Sakit Dr. Pirngadi Medan. ${ }^{23}$

Gaya kepemimpinan demokratis menjadi gaya kepemimpinan yang paling dominan di antara staf administrasi FKM UNDIP. Pemimpin yang memiliki gaya kepemimpinan demokratis cenderung untuk menghargai kemampuan dan sifat bawahannya, memberikan kesempatan untuk berbicara dan berpendapat kepada bawahannya, serta bersifat informatif kepada bawahannya. Pemimpin dengan gaya kepemimpinan demokratis juga biasanya memberikan dukungan sosial kepada bawahannya.

\section{KESIMPULAN}

Tidak adanya hubungan yang signifikan antara karakteristik demografi pekerja (usia, jenis kelamin, status pernikahan, pendidikan, masa kerja), beban kerja mental, dan gaya kepemimpinan terhadap burnout pada staf administrasi FKM UNDIP.

\section{SARAN}

1. Bagi Instansi

Dengan adanya temuan $75,9 \%$ staf administrasi mengalami burnout tingkat sedang, pihak instansi dapat melakukan penyesuaian beban kerja dengan kapasitas dari masing-masing staf, seperti dengan cara memberikan tugas kerja dengan tingkat kesulitan yang sama dengan kemampuan yang dimiliki masing-masing staf. Hal tersebut bertujuan untuk menekan beban kerja yang melebihi kemampuan atau kapasitas dari staf yang pada akhirnya berpotensi memberikan burnout.

2. Bagi Pekerja/Staf Administrasi FKM UNDIP

Bagi Pekerja/staf administrasi yang melakukan work from home disarankan untuk menentukan waktu kerja dan waktu istirahat yang jelas, seperti kapan mulai bekerja, kapan waktu istirahat dan makan siang, kapan harus berhenti bekerja. Dengan mengatur jadwal dapat menekan perasaan lelah, penat, dan juga stres. Disarankan juga bagi staf work from home untuk memiliki tempat khusus bekerja di rumah agar fokus dan mood kerja tetap terjaga. Melakukan break selama $10-$ 15 menit di sela - sela waktu kerja untuk peregangan dan refreshing baik bagi staf yang melakukan work from home maupun work from office.

3. Bagi Peneliti

Bagi peneliti selanjutnya dapat melakukan penelitian terhadap faktor-faktor lain yang memengaruhi burnout seperti lingkungan kerja atau iklim kerja, karakteristik jabatan, kepribadian individu, hingga job attitudes.

\section{REFERENSI}

1. Setiawan MN, Hariyono W, Mulasari SA. PENERAPAN KESELAMATAN DAN KESEHATAN KERJA PADA CV. CIPTA MANDIRI DI KABUPATEN KENDAL. J Kesehat Masy (Journal Public Heal. 2013;5(2).

2. Pemerintah Republik Indonesia. UU No. 1 Tahun 1970 Tentang Keselamatan Kerja [Internet]. Journal of Chemical Information and Modeling 1970 p. 1689-99. Available from:

https://peraturan.bpk.go.id/Home/Details/47 


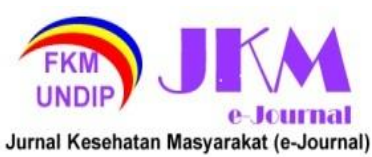

614/uu-no-1-tahun-1970

3. Manajemen Administrasi Perkantoran Modern - Google Buku [Internet]. [cited 2020 Dec 20]. Available from: https://books.google.co.id/books?id=F_5Th 5XQf-

$A C \&$ printsec $=$ frontcover\#v=onepage $\& q \& f=f$ alse

4. Kementrian Kesehatan RI. PERMENKES No. 48 tahun 2016 Tentang Standar Keselamatan dan Kesehatan Kerja [Internet]. 2016. Available from: https://peraturan.bpk.go.id/Home/Details/11 3097/permenkes-no-48-tahun-2016

5. Nissa UN, Amalia S. Pengaruh Keselamatan dan Kesehatan Kerja Terhadap Kinerja Karyawan. J Ris Bisnis dan Investasi [Internet]. 2018 Feb 20 [cited 2020 Dec 20];3(3):69. Available from: http://journal.pnm.ac.id/index.php/epicheiris i/article/view/409/xml

6. Hartanti ID, Supriyanto A, Ulfatin N. MANAJEMEN PENANGANAN BURNOUT DALAM MENINGKATKAN KINERJA TENAGA ADMINISTRASI SEKOLAH. J Adm dan Manaj Pendidik [Internet]. 2018 [cited 2020 Sep 13];1(3):347-57. Available from: http://karyailmiah.um.ac.id/index.php/ASP/article/view/ 74197

7. Zasyatin R. SIKAP TERHADAP PENGEMBANGAN KARIR DENGAN BURNOUT PADA KARYAWAN. J IIm Psikol Terap [Internet]. 2013 [cited 2020 Dec 20];01(02):260-72. Available from: http://ejournal.umm.ac.id/index.php/jipt/artic le/view/1582

8. Gorvett Z. WHO jabarkan "fenomena kelelahan bekerja", apa itu dan bagaimana mengatasinya? BBC Capital [Internet]. 2019 [cited 2020 Dec 20]; Available from: https://www.bbc.com/indonesia/vert-cap48604523

9. Maslach C, Schaufeli WB, Leiter MP. Job Burnout. Annu Rev Psychol [Internet]. 2001 Feb 28 [cited 2020 Dec 20];52(1):397-422. Available from: http://www.annualreviews.org/doi/10.1146/ annurev.psych.52.1.397

10.Saputri W. LAPANGAN PT. MULTI TERMINAL INDONESIA TAHUN 2017 [Internet]. 2017 [cited 2020 Dec 20]. Available from: http://repository.uinjkt.ac.id/dspace/handle/ 123456789/35890

11.Swasti KG, Ekowati W, Rahmawati E. Faktor-Faktor yang Mempengaruhi Burnout pada Wanita Bekerja di Kabupaten
Banyumas. J Keperawatan Soedirman [Internet]. 2018 [cited 2020 Dec 20];12(3):190. Available from: http://jks.fikes.unsoed.ac.id/index.php/jks/ar ticle/view/738/423

12. Hunter B, Fenwick J, Sidebotham DM, Henley DJ. Midwives in the United Kingdom: Levels of burnout, depression, anxiety and stress and associated predictors. Midwifery. 2019 Dec 1;79:102526.

13.Indra Prakoso D, Setyaningsih Y, Kurniawan B, Kesehatan Masyarakat F. HUBUNGAN KARAKTERISTIK INDIVIDU, BEBAN KERJA, DAN KUALITAS TIDUR DENGAN KELELAHAN KERJA PADA TENAGA KEPENDIDIKAN DI INSTITUSI KEPENDIDIKAN X. J Kesehat Masy [Internet]. 2018 May 1 [cited 2020 Dec 20];6(2):88-93. Available from: http://ejournal3.undip.ac.id/index.php/jkm

14.Marla F. Beban Kerja Mental Dan Kesiapan Pensiun Dengan Tingkat Deperesi Pegawai Negeri Sipil (PNS) Di Universitas Jember [Internet]. 2017 [cited 2020 Dec 20]. Available from: https://repository.unej.ac.id/handle/123456 789/84843

15.Rsud Krmt Wongsonegoro Kota Semarang D, Semarang N, Sa N, Baju Widjasena D, Peminatan Keselamatan dan Kesehatan Kerja M, UNDIP Semarang $F$, et al. FAKTOR-FAKTOR YANG BERHUBUNGAN DENGAN STRES KERJA PADA STAF ADMINISTRASI RUANGAN DI RSUD K.R.M.T. WONGSONEGORO KOTA SEMARANG. J Kesehat Masy [Internet]. 2018 May 1 [cited 2020 Dec 20];6(2):94-102. Available from: http://ejournal3.undip.ac.id/index.php/jkm

16.Indilusiantari V, Meliana I. Faktor-faktor yang berhubungan dengan burnout syndrome pada pegawai di direktorat bina kesehatan kerja dan olahraga kementerian kesehatan republik indonesia jakarta selatan tahun 2019. J IIm Kesehat [Internet]. 2015;7(1):28-33. Available from: http://lp3m.thamrin.ac.id/upload/jurnal/JUR NAL-1519366126.PDF

17. Marchand A, Blanc ME, Beauregard N. Do age and gender contribute to workers' burnout symptoms? Occup Med (Chic III) [Internet]. 2018 [cited 2021 Jun 28];68(6):405-11. Available from: https://pubmed.ncbi.nlm.nih.gov/29912439/

18. Yusnilawati IM. View of Faktor-Faktor yang Mempengaruhi Kejadian Burnout Pada Perawat di Ruang Instalasi Rawat Inap 
RSUD Raden Mattaher dan Abdul Manap Jambi Tahun 2017 [Internet]. Jurnal IImiah IImu Terapan Universitas Jambi. 2018 [cited 2021 Jun 28]. Available from: https://online-

journal.unja.ac.id/JIITUJ/article/view/5984/9 221

19.Fyana L, Rozali YA. Perbedaan Burnout Ditinjau Dari Jenis Kelamin Pada Karyawan Bank Abc. J Psikol. 2018;962(9):1-8.

20.Darmawan AAYP, Silviandari IA, Susilawati IR. Hubungan Burnout dengan Work-Life Balance pada Dosen Wanita. Mediapsi. 2015;01(01):28-39.

21.Zulfiqar M, Rizqiansyah A. HUBUNGAN ANTARA BEBAN KERJA FISIK DAN BEBAN KERJA MENTAL BERBASIS ERGONOMI TERHADAP TINGKAT KEJENUHAN KERJA PADA KARYAWAN PT JASA MARGA (PERSERO) TbK CABANG SURABAYA GEMPOL. Vol. 6, Jurnal Sains Psikologi, Jilid. 2017.

22.Ernawati R, Suhardi B, Pujiyanto E. Using the NASA task load index and heart rate to evaluate vocational student's mental and physical workload. AIP Conf Proc [Internet]. 2019;2097(May). Available from: https://doi.org/10.1063/1.5098232

23.Teuku Reza Budiansya. Hubungan Gaya Kepemimpinan Kepala Ruangan dengan Burnout Perawat Pelaksana di Ruang Rawat Inap Rumah Sakit Dr. Pirngadi Medan [Internet]. [cited 2021 Jun 28]. Available from: https:/textid.123dok.com/document/wyee7x0y7hubungan-gaya-kepemimpinan-denganburnout-1-uji-normalitas.html 